\title{
A MICRO METHOD FOR BLOOD UREA AND AN AUTOMATIC URINE COLLECTOR FOR UREA CLEARANCE IN INFANTS
}

\author{
BY LEE E. FARR \\ (From the Hospital of the Rockefeller Institute for Medical Research, Nezv York)
}

(Received for publication August 12, 1935)

\section{Hypobromite micro method for blood urea}

The blood is precipitated according to the method of Steiner, Urban and West (1932), and the urea is determined manometrically by the hypobromite reaction, as applied by Van Slyke and Kugel (1933).

Twenty-five hundredths cubic centimeters of blood is laked in $12.0 \mathrm{cc}$. of distilled water which has been measured into a conical centrifuge tube with calibrated volumetric pipettes. The blood is stirred to ensure adequate mixing and $0.25 \mathrm{cc}$. of 17 per cent $\mathrm{FeSO}_{4} \cdot \mathrm{H}_{2} \mathrm{O}$ is added and mixed thoroughly with a stirring rod. Then 0.2 to 0.4 gram of solid $\mathrm{BaCO}_{3}$ is added. This is most conveniently done by using a small ladle which has previously been measured to contain the correct weight of $\mathrm{BaCO}_{3}$. An excess of $\mathrm{BaCO}_{3}$ does not injure the analysis. The mixture is thoroughly stirred until the precipitate begins to flocculate. Settling is rapid, and the supernatant liquid should be clear. If there is a yellowish tinge, some additional $\mathrm{BaCO}_{3}$ should be added and the contents thoroughly mixed. The tube is then centrifuged for 15 minutes at 2500 R.P.M. or more, and filtered through a small $(5$ or $7 \mathrm{~cm}$.) filter paper into a $25 \mathrm{cc}$. Erlenmeyer flask. Usually 10.5 to $11.0 \mathrm{cc}$. of filtrate are obtained.

For the urea determination $5 \mathrm{cc}$. of filtrate are transferred to the chamber of the Van Slyke-Neill manometric apparatus by means of an Ostwald bulb pipette. The $5 \mathrm{cc}$. of filtrate represent 0.1 cc. of the original whole blood sample. The chamber is sealed, and is evacuated and shaken for two minutes to free the solution of dissolved gases. These are expelled, and $1.5 \mathrm{cc}$. of the hypobromite solution is run into the chamber, which is then sealed, evacuated and shaken for the necessary reaction time, about $11 / 2$ minutes, at ordinary room temperature. The pressure of the gas evolved is measured with the gas occupying a volume of $0.5 \mathrm{cc}$. The filtrate from $0.25 \mathrm{cc}$. of blood suffices for duplicate analyses.
An empirical correction of $1 \mathrm{mgm}$. urea nitrogen per $100 \mathrm{cc}$. blood is subtracted when the uncorrected value exceeds $10 \mathrm{mgm}$., but not when it is less than $10 \mathrm{mgm}$.

It is not necessary to remove the barium in determining the urea by this method. If $0.25 \mathrm{cc}$. of blood is not available it is possible to perform the analysis on as little as $0.1 \mathrm{cc}$. of blood, though the accuracy of the result is correspondingly lessened.

The results when $0.25 \mathrm{cc}$. of blood are used are accurate to within 5 per cent of the true value unless the blood urea nitrogen is below $10 \mathrm{mgm}$. per cent.

\section{Infant urine collector and annunciator apparatus}

The following apparatus was developed in order that the rate of urine excretion in infants could be determined as exactly as in adults. This allows one to calculate the urea clearance, for which it is necessary to be certain that all of the voided urine is collected, and that the interval during which the urine is excreted is accurately timed.

A $1000 \mathrm{ml}$. wide-mouth bottle is used as the container for the apparatus (see Figure 1). This is kept clean so that any urine which escapes from the collection cup can be recovered and measured. The mechanical parts are fixed to an ordinary rubber stopper $5 \mathrm{~cm}$. in diameter. Through this stopper in an eccentric position is led a $3 / 8$ inch glass tube $(U)$ which is curved after it passes into the bottle so that the lower opening is below the center of the cork and over or extending into the mouth of the $30 \mathrm{ml}$. beaker that is used for the collection of the specimen. The beaker is suspended from a spring arm $(C)$, the suspending string passing through the center of the cork. It is connected with the beaker by a hook $(D)$ which holds the beaker handle $(E)$ which is connected to the beaker by being wound tightly about it. This system must be so arranged that the beaker swings freely. The diameter of the beaker. is sufficiently less than that of the mouth of the 

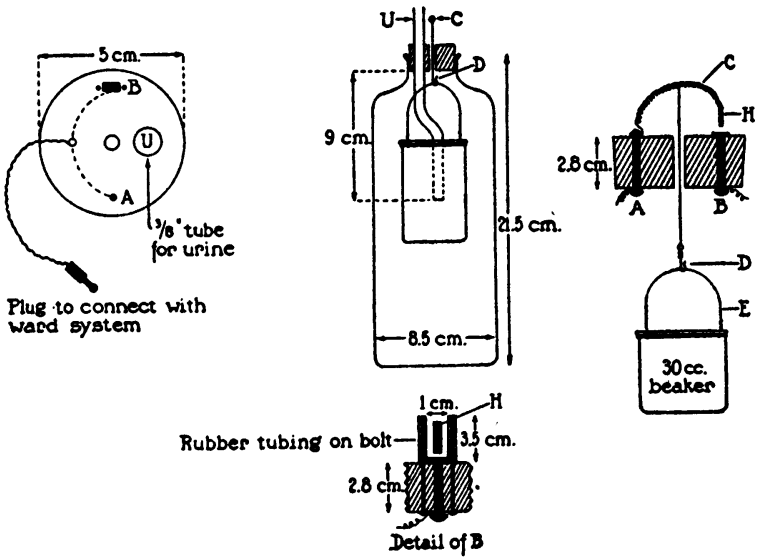

Fig. 1. Details of Urine Collector and Annunciator For symbols, see text.

TABLE I

Factors by which $P_{N_{2}}$ is multiplied to give urea or urea nitrogen per $100 \mathrm{cc}$. of blood

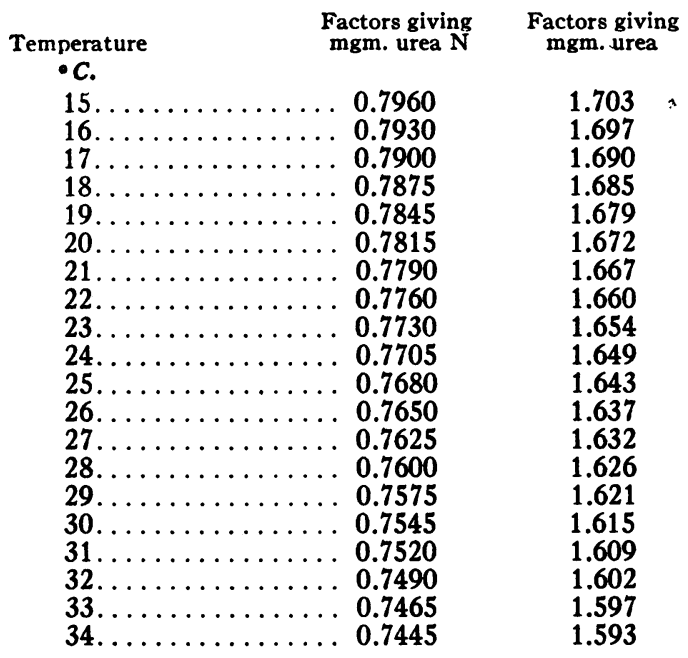

bottle to allow free withdrawal of the beaker when full. The alarm apparatus consists of a wire spring arm $(C)$ to which the beaker string is fastened at about the middle. One connection from the wall plug $(A)$ is connected to the base of this spring arm, the other is fastened to the contact $(B)$. The wire itself is led through the cork, and the connections are made on the lower side of the cork. The spring contact is so adjusted that 2 to $3 \mathrm{cc}$. of urine will depress the beaker and arm sufficiently to make contact. On either side of the flat contact head is placed a long screw which is covered with rubber tubing. (See $B$ in detail, Figure 1). This acts as a guide for

TABLE II

Analyses of blood showing comparisons with macro urease determinations

\begin{tabular}{|c|c|c|c|c|c|}
\hline Sample & $\mathbf{P}_{\mathrm{N}_{2}}$ & $\begin{array}{c}\text { Tempera- } \\
\text { ture }\end{array}$ & $\begin{array}{c}\text { Urea } N \\
\text { per } \\
100 \mathrm{cc} .\end{array}$ & $\begin{array}{c}\text { Urea N } \\
\text { per } \\
100 \mathrm{cc} . \\
\text { average } \\
\text { value }\end{array}$ & $\begin{array}{c}\text { Urea } N \\
\text { per } 100 \text { cc. } \\
\text { by macro } \\
\text { urease } \\
\text { method }\end{array}$ \\
\hline $\mathbf{R}_{\mathbf{2}}$ & $\begin{array}{l}m m . \\
10.5 \\
10.8\end{array}$ & $\begin{array}{l}{ }^{\circ} C . \\
27.5\end{array}$ & $\begin{array}{r}\text { mgm. } \\
8.00 \\
8.20\end{array}$ & $\begin{array}{l}m g m . \\
8.1^{*}\end{array}$ & $\begin{array}{l}m g m . \\
8.53\end{array}$ \\
\hline $\mathbf{M}$ & $\begin{array}{l}23.8 \\
24.8\end{array}$ & 25.5 & $\begin{array}{l}16.95 \\
17.80\end{array}$ & 17.37 & 17.81 \\
\hline C & $\begin{array}{l}16.3 \\
14.8\end{array}$ & 24.5 & $\begin{array}{l}11.35 \\
10.20\end{array}$ & 10.7 & 9.40 \\
\hline $\mathbf{R}$ & $\begin{array}{r}9.5 \\
10.5\end{array}$ & 24.0 & $\begin{array}{l}7.30 \\
8.10\end{array}$ & $7.7^{*}$ & 8.05 \\
\hline$P$ & $\begin{array}{l}207.5 \\
210.0\end{array}$ & 27.0 & $\begin{array}{l}157.10 \\
158.80\end{array}$ & 157.9 & 160.20 \\
\hline
\end{tabular}

* Empirical correction of $1 \mathrm{mgm}$. not subtracted for urea nitrogen values below $10 \mathrm{mgm}$. per $100 \mathrm{cc}$.

the spring arm and ensures contact in the proper manner on all occasions. The two wires leading from the apparatus (as $A$ and $B$ ) are connected to a plug which fits into the ward annunciator system. The urine is obtained from the child in the customary manner. On male infants the penis is inserted into an adapter tube of such a size as to avoid compression. This is held in place by a urinal binder, which consists of two strips of cotton material forming an $\mathrm{X}$ (see Figure 2). At the center of the $\mathrm{X}$ is made a hole which allows the adapter tube to slip through but which will not permit the lip of the tube to pass. The edges of the hole must be reinforced by buttonhole stitching to prevent tearing and stretching. The adapter is then held firmly in place by

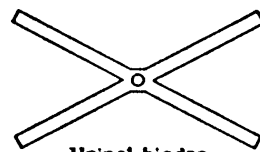

Usinal bindes

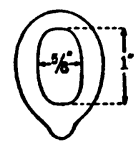

Adapter tube for female Adapter tube for females opening and flange

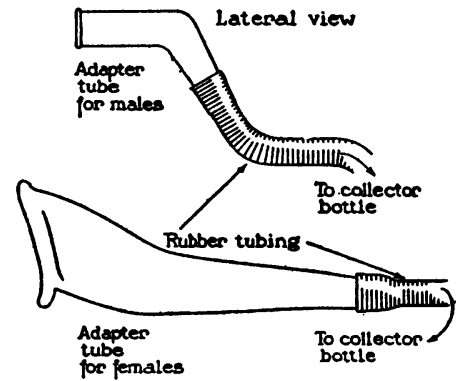

Fig. 2. Details of Adapter for Urine Collector 
bringing the arms of the $\mathrm{X}$ around the child and pinning. For female infants the same binder may be used but a different shaped adapter tube is used. From the adapter tube the urine is led through a soft rubber tube directly over the foot of the bed to the alarm bottle. It is advantageous to raise the head of the bed and usually it is necessary to place restraints on the child's ankles. No other restraints are ordinarily required. Thus, when the child voids, the beaker is filled, depressing the spring arm and making contact. This rings the buzzer on the call board, and it is merely necessary to note the time in order to determine any series of intervals desired. The specimen of urine in the beaker is collected, and the beaker replaced ready for the next specimen.

Clearances which have been calculated from data obtained in this fashion are comparable in every way to those done on older patients and on the same patient when voluntary control could be exercised.

\section{BIBLIOGRAPHY}

Steiner, Alexander, Urban, Frank, and West, Edward S., Iron and thorium precipitation of biological fluids for sugar and other analyses. J. Biol. Chem., 1932, 98, 289.

Van Slyke, D. D., and Kugel, Victor H., Improvements in manometric micro-Kjeldahl and blood urea methods. J. Biol. Chem., 1933, 102, 489. 